\title{
Corrupção e composição dos gastos governamentais: evidências a partir do Programa de Fiscalização por Sorteios Públicos da Controladoria-Geral da União
}

\author{
Olavo Venturim Caldas \\ Controladoria-Geral da União (CGU) / Secretaria de Transparência e \\ Prevenção da Corrupção (STPC) \\ Brasília / DF - Brasil \\ Cristiano Machado Costa \\ Universidade do Vale do Rio dos Sinos (Unisinos) / Programa de \\ Pós-Graduação em Ciências Contábeis \\ São Leopoldo / RS - Brasil \\ Marcelo Sanches Pagliarussi \\ Universidade de São Paulo (USP) / Faculdade de Economia, Administração e \\ Contabilidade de Ribeirão Preto (FEA-RP) \\ Ribeirão Preto / SP - Brasil
}

\begin{abstract}
Este trabalho investiga a relação entre corrupção e composição dos gastos governamentais nos municípios brasileiros. Estudos anteriores, utilizando dados para países, apontam que a corrupção distorce a alocação dos recursos públicos, elevando os gastos com defesa nacional e diminuindo os gastos com saúde e educação. A partir de uma medida de corrupção criada a partir dos relatórios da ControladoriaGeral da União, os resultados de estimações por meio de mínimos quadrados ordinários indicam que nos municípios brasileiros ocorre um fenômeno diferente. Verifica-se uma relação positiva e significativa entre corrupção e gastos com educação e saúde. Esse fenômeno se deve primordialmente ao poder de discricionariedade das despesas municipais e das legislações vigentes no país, que exigem dispêndios mínimos com educação e saúde como percentual da receita dos municípios.
\end{abstract}

Palavras-chave: corrupção; composição de gastos governamentais; rent-seekers.

DOI: http://dx.doi.org/10.1590/0034-7612140185

Artigo recebido em 4 set. 2014 e aceito em 6 ago. 2015. 
La corrupción y la composición del gasto público: evidencia desde el Programa de Sorteo Público de Inspección de la Controladoria-Geral da União

Este trabajo investiga la relación entre la corrupción y la composición del gasto público en los municipios brasileños. Estudios previos, utilizando los datos de los países, muestran que la corrupción distorsiona la distribución de los recursos públicos, aumentando el gasto en defensa nacional y disminuyendo los gastos en salud y educación. Utilizando una medida de la corrupción derivada de los informe de la Controladoria-Geral da União, los resultados de estimaciones MCO indican una distorsión diferente de la que ocurre en el nivel municipal. Encontramos una relación positiva y significativa entre la corrupción y el gasto en educación y salud. Este fenómeno es sobre todo una consecuencia del poder discrecional en el ámbito municipal y las leyes federales que requieren gastos mínimos en educación y salud, como porcentaje de los ingresos para los municipios.

Palabras clave: corrupción; composición del gasto público; rentistas.

Corruption and the composition of governmental expenditure: evidence from Controladoria-Geral da União's Public Random Drawing Inspection Program

This paper investigates the relationship between corruption and the composition of governmental expenditure in Brazilian municipalities. Previous studies using data for countries show that corruption distorts the allocation of public resources, which increases expenditure on national defense and decreases expenditure on health and education. Using a measure of corruption derived from Controladoria-Geral da União's reports, results of OLS estimates indicate that a different phenomenon occurs in Brazilian municipalities. A positive and significant relationship between corruption and expenditure on education and health is found. This phenomenon is primarily a consequence of the discretionary power of municipal expenditure and federal laws, which require minimum expenditures on education and health as a percentage of revenue for municipalities.

KEYWORDs: corruption; composition of governmental expenditure; rent-seekers.

\section{Introdução}

É muito difícil no Brasil exagerar o significado econômico e social da corrupção, uma vez que o assunto parece estar sempre em pauta na sociedade brasileira. Na academia, uma linha de pesquisa em estudos sobre corrupção investiga suas consequências econômicas e sociais. Entre os resultados encontrados destacam-se diversos efeitos negativos, como a redução do crescimento econômico, a diminuição de investimentos e receitas públicas e problemas de manutenção de infraestrutura pública (Barro, 1991; Shleifer e Vishny, 1993; Mauro, 1995; Tanzi e Davoodi, 1997).

Outra linha de pesquisa investiga como a corrupção distorce a alocação dos gastos públicos. Mauro (1998) comparou os gastos de países com educação em relação ao Produto Interno Bruto (PIB) a índices de percepção de corrupção e encontrou relação negativa entre gastos do governo com educação e corrupção. Gupta e colaboradores (2001) se concentraram em estudar a relação entre corrupção e gastos governamentais em despesas militares, também relativos ao PIB dos países, e observaram que a corrupção está associada a gastos maiores com despesas militares. 
Estudos realizados no Brasil investigaram causas e consequências da corrupção. Albuquerque e Ramos (2006) focaram os determinantes da corrupção no nível municipal e sugerem que a combinação envolvendo menores salários e maior poder discricionário está associada à corrupção. Adicionalmente, como os prefeitos se preocupam com seus ganhos futuros, a possibilidade de reeleição funciona como restrição à corrupção no primeiro mandato.

Sodré e Alves (2010) investigaram a relação entre emendas parlamentares ao orçamento e corrupção no âmbito municipal e observaram que o aumento da corrupção parece estar mais relacionado com o fato de um município receber alguma emenda do que com o valor total das emendas recebidas.

Ferraz e Finan (2008) estudaram os efeitos da divulgação de práticas corruptas nos governos locais no resultado das eleições municipais no Brasil. Os autores concluem que os eleitores não apenas se preocupam com a corrupção, mas, de posse das informações relevantes, eles atualizam suas crenças a respeito da idoneidade do candidato e punem os prefeitos corruptos por meio do seu voto nas urnas.

Ferraz, Finan e Moreira (2012) sugerem que o desvio de verbas por corrupção resulta em perda da qualidade da educação oferecida aos cidadãos, uma vez que nos municípios com maior incidência de corrupção as escolas têm infraestrutura pior, os professores recebem menos treinamento e relatam maior preocupação com a falta de recursos. Como resultado, o desempenho dos alunos em exames padronizados foi significativamente menor em municípios com maiores taxas de corrupção.

Bologna e Ross (2015), usando medidas de corrupção baseadas nos dados das auditorias realizadas pela Controladoria-Geral da União, observaram que a corrupção reduz o número de empresas operando em uma dada região, e esse efeito é mais forte com o passar do tempo, o que sugere que a corrupção é mais danosa à atividade econômica no longo prazo.

Uma lacuna observada na literatura desenvolvida com dados brasileiros é a inexistência de estudos investigando a relação entre o nível de corrupção e a composição dos gastos. Mauro (1998) e Gupta e colaboradores (2001) sugerem que a corrupção resulta em distorções orçamentárias, pois o sigilo requerido pelas transações corruptas pode levar agentes a direcionar a composição dos gastos governamentais de áreas prioritárias como saúde e educação para áreas não usuais como defesa e grandes obras de infraestrutura, nas quais é mais fácil se apropriar do recurso público (Shleifer e Vishny, 1993). Entretanto, diferenças no ambiente institucional brasileiro fazem com que as conclusões de Mauro (1998) e Gupta e colaboradores (2001) não sejam necessariamente válidas no Brasil. Por exemplo, a Constituição brasileira define limites mínimos obrigatórios de gastos públicos municipais em áreas como saúde e educação.

O presente artigo teve como objetivo analisar a relação entre corrupção e composição dos gastos governamentais nos municípios do Brasil. Diferentemente dos estudos de Mauro (1998), Ades e Di Tella (1999) e Gupta e colaboradores (2001), que foram baseados em dados econômicos e orçamentários agregados ou índices de percepção de corrupção, no presente estudo utilizam-se dados desagregados de corrupção e da composição de gastos municipais para identificar os grupos de despesas mais ou menos associados à corrupção. 
Outro diferencial deste trabalho está na forma de mensuração da corrupção. Foram utilizados dados de irregularidades encontradas nas fiscalizações e auditorias da CGU relacionadas a desvios de recursos, fraudes e aquisições superfaturadas no nível dos municípios. Tal abordagem é mais objetiva para mensurar o fenômeno, considerando as críticas quanto à utilização de índices de percepção de corrupção em estudos empíricos (Olken, 2009; Ferraz, Finan e Moreira, 2012).

O presente estudo contribui com a literatura sobre corrupção e composição dos gastos governamentais ao demonstrar a influência dos aspectos institucionais na relação entre os dois conceitos. Ao considerar os aspectos legais que compõem o ambiente institucional em que os administradores municipais atuam, o presente estudo ilustra como o raciocínio teórico da rent-seeking theory precisa ser adaptado devido às exigências constitucionais de gasto mínimo como percentual das receitas municipais. Hoje, a legislação brasileira exige que as despesas nas funções educação e saúde sejam equivalentes a no mínimo 40\% dos recursos do município ( $25 \%$ para educação e $15 \%$ para a saúde). Além disso, a Lei de Responsabilidade Fiscal impõe um teto de $60 \%$ nas despesas com pessoal.

Os resultados obtidos indicam que o ambiente institucional brasileiro constitui um determinante na análise para os municípios brasileiros. Os coeficientes estimados a partir de uma amostra de mais de 700 municípios brasileiros indicam que a corrupção está associada à composição dos gastos governamentais nos governos locais, porém de uma maneira diferente da reportada nos estudos anteriores que conduziram análises no nível dos países, como Mauro (1998) e Gupta e colaboradores (2001). Na função assistência social, por exemplo, foi observada uma relação negativa entre o nível de corrupção do município e a parcela destinada a essa função. Isso indica pouca atratividade para prática de desvios em pensões e benefícios sociais no nível municipal. Por outro lado, as evidências demonstram associação positiva entre o nível de corrupção e os gastos em educação e saúde, indicando uma possível atuação de rent-seekers nessas áreas, possivelmente devido a maior facilidade no desvio desses recursos. Os resultados do presente artigo sugerem que, contrariamente ao que foi previamente observado na literatura, as funções em que os administradores municipais possuem maior poder de discricionariedade na alocação dos gastos são justamente as de saúde e educação.

\section{Características relevantes do ambiente institucional brasileiro}

A seguir serão apresentados os aspectos institucionais do ambiente brasileiro, pois tais aspectos podem criar incentivos que influenciam a expectativa de comportamento dos agentes.

\subsection{Despesas municipais e transferências da União}

A Lei no 4.320 (Brasil, 1964) define as Normas Gerais de Direito Financeiro para elaboração e controle dos orçamentos dos entes da Federação Brasileira. O art. 2º da referida lei prevê 
que "A Lei do Orçamento conterá a discriminação da receita e despesa de forma a evidenciar a política econômica financeira e o programa de trabalho do Governo" (Brasil, 1964), e essa descriminação em relação à despesa será realizada por funções de governo, que foram detalhadas no anexo 5 da mesma Lei. As funções de governo são definidas na Portaria no 42, do Ministério do Orçamento e Gestão (Brasil, 1999), como o "maior nível de agregação das diversas áreas de despesa que competem ao setor público".

A partir das bases de dados da série "Finanças do Brasil - Dados Contábeis dos Municípios", de 2005 a 2010, disponibilizadas pela Secretaria do Tesouro Nacional (STN), foram coletados e consolidados na tabela 1 os dados da execução orçamentária da despesa dos municípios brasileiros do período de 2005 a 2010, organizados por função de governo. Destacam-se os dispêndios com saúde e educação, que, somados, constituíram aproximadamente 48\% das despesas dos municípios brasileiros em 2010.

Tabela 1

Despesas por função de governo dos municípios do Brasil - 2005-10 (milhões de reais)

\begin{tabular}{|lcccccc|}
\hline Funções de governo & 2005 & 2006 & 2007 & 2008 & 2009 & 2010 \\
\hline Educação & 23.990 & 27.494 & 30.319 & 33.300 & 36.655 & 38.889 \\
Saúde & 21.493 & 24.682 & 26.561 & 29.567 & 33.098 & 35.102 \\
Administração & 13.844 & 15.693 & 16.464 & 16.959 & 18.736 & 19.283 \\
Urbanismo & 10.195 & 12.670 & 13.624 & 16.098 & 14.260 & 16.426 \\
Assistência Social & 4.861 & 5.204 & 6.538 & 7.298 & 7.660 & 7.370 \\
Outras & 21.292 & 25.614 & 27.543 & 31.064 & 31.707 & 34.994 \\
Total Geral & 95.675 & 111.357 & 121.049 & 134.286 & 141.817 & 152.060 \\
\hline
\end{tabular}

Fonte: Elaborada pelos autores com dados da série "Finanças do Brasil - Dados Contábeis dos Municípios" da STN. Disponível em: <www.tesouro.fazenda.gov.br/pt/prefeituras-governos-estaduais/sobre>. Acesso em: 27 mar. 2013.

Nota: Valores aos preços constantes de 2000, deflacionados pelo IPCA.

Para detalhar mais a dinâmica da composição dos gastos municipais, a tabela 2 traz informações disponíveis no Portal da Transparência do Governo Federal referentes às transferências da União para os municípios brasileiros do período de 2005 a 2010, também organizadas por função de governo.

Cabe ressaltar a magnitude de certas transferências, vis-à-vis o total gasto pelos municípios. No último ano analisado, 2010, as transferências para a função educação foram da ordem de $38 \%$ do total, enquanto as transferências para a função saúde somaram $43 \%$ do total despendido pelos municípios nessa função. Esse resultado aponta para uma grande dependência dos municípios brasileiros das transferências federais. Complementarmente, dissociar as transferências das despesas diretas é importante porque os mecanismos que originam as transferências e os gastos diretos são diferentes, bem como o poder de discricionariedade na execução de despesas com verbas oriundas de transferências federais. 
Tabela 2

Transferências da União, por função de governo, para municípios do Brasil - 2005-10 (milhões de reais)

\begin{tabular}{|lcccccc|}
\hline Transferências por função & 2005 & 2006 & 2007 & 2008 & 2009 & 2010 \\
\hline Encargos Especiais & 20.104 & 21.579 & 23.074 & 27.647 & 24.978 & 25.682 \\
Saúde & 7.845 & 11.388 & 14.599 & 13.803 & 13.916 & 15.288 \\
Educação & 6.467 & 6.024 & 7.967 & 10.288 & 13.147 & 14.863 \\
Assistência Social & 4.750 & 5.736 & 6.249 & 6.826 & 7.436 & 5.674 \\
Urbanismo & 233 & 480 & 522 & 1.135 & 751 & 640 \\
Outras & 1.797 & 2.546 & 3.170 & 3.920 & 3.588 & 4.1322 \\
Total Geral & 41.196 & 47.753 & 55.581 & 63.619 & 63.816 & 66.279 \\
\hline
\end{tabular}

Fonte: Elaborada pelos autores com dados do Portal da Transparência do Governo Federal. Disponível em: <www.portaldatransparencia. gov.br/downloads/>. Acesso em: 3 abr. 2013.

Nota: Valores aos preços constantes de 2000, deflacionados pelo IPCA.

\subsection{Limites obrigatórios de gastos públicos municipais}

Por obrigação constitucional, todos os anos os municípios brasileiros devem destinar no mínimo $25 \%$ de toda a receita resultante de impostos próprios ou resultantes de transferências da União e estados na educação infantil e no ensino fundamental (Brasil, 1988a, art. 212). Além disso, 60\% das transferências do Fundo da Educação Básica (Fundeb) devem ser aplicados na remuneração dos profissionais do magistério da educação básica (Brasil, 1988b, art. 60).

Também como consequência da legislação federal, os municípios brasileiros devem gastar no mínimo 15\% da receita de impostos próprios e transferidos em ações e serviços da saúde (Emenda Constitucional no 29/2000). Esses dois requerimentos basicamente obrigam os municípios a alocar no mínimo 40\% das receitas e transferências em saúde e educação, tornando essas duas funções as principais na administração pública municipal brasileira. A obrigatoriedade de alcançar o mínimo exigido pela legislação frequentemente resulta em gastos não prioritários, gerando incentivos para que os agentes se engajem em atividades consideradas corrupção.

A Lei de Responsabilidade Fiscal (LRF) também tem potencial para exercer efeito importante na discricionariedade de alocação de recursos dos administradores municipais. Entre outras restrições, a LRF define que os gastos municipais com pessoal devem limitar-se a 60\% do total arrecadado. A LRF tende a elevar os gastos com máquinas, equipamentos e materiais de administração.

Assim, espera-se que as exigências legais combinadas criem incentivos para que rentseekers busquem uma maior alocação de recursos públicos justamente na compra de produtos classificados como bens de capital e custeio, e serviços nas áreas de saúde e educação. 


\subsection{O Programa de Fiscalização por Sorteios Públicos da CGU}

O Programa de Fiscalização por Sorteios Públicos (PFSP) da Controladoria-Geral da União (CGU) foi idealizado para inibir a corrupção em todas as esferas da administração pública (Brasil, 2003). Criado em abril de 2003, o programa é baseado na utilização de sorteios públicos, nos mesmos moldes do sistema de sorteio das loterias da Caixa Econômica Federal, para definir de forma aleatória os municípios e estados que serão fiscalizados pela ControladoriaGeral da União (Brasil, 2003).

Na metodologia do PFSP da CGU, em cada sorteio são definidos 60 municípios com até 500 mil habitantes, exceto as capitais estaduais. Tais municípios receberão as equipes de auditores, em média com 10 a 15 servidores, para examinar processos, documentos e saldos financeiros, realizar inspeções e fiscalizações em obras e serviços, e manter contato com a população do município (Brasil, 2003).

Ao final dos trabalhos de auditoria e fiscalização, os auditores da CGU elaboram um relatório contendo informações detalhadas das constatações e de suas evidências, inclusive por meio de fotografias e vídeos. Por fim, os relatórios do PFSP são encaminhados aos Ministérios do governo federal para ajustes nas políticas públicas e enviados aos órgãos de defesa do Estado, para que atuem em casos de irregularidades ou desvios (Brasil, 2003). Esse sistema de sorteio, combinado com os dados levantados pelos auditores da CGU, constituiu a base usada para elaborar uma medida de corrupção no presente estudo, que será apresentada na seção 5 .

\section{Estudos anteriores sobre corrupção no Brasil e no mundo}

A associação entre corrupção e composição das despesas dos governos tem sido investigada com base no argumento de que a interação de fatores como a intensidade da competição em um dado mercado, o nível de desenvolvimento tecnológico do produto sendo adquirido e o grau de discricionariedade do agente público na aquisição do bem ou serviço cria dificuldades ou facilidades para a criação e captura de renda por meio de transações corruptas (Mauro, 1998; Ades e Di Tella, 1999; Gupta et al., 2001). Por exemplo, Mauro (1998) analisou a relação entre índices de percepção de corrupção e componentes dos gastos públicos, em função do PIB, e utilizou dados de mais de 100 países e da média do índice de percepção de corrupção produzido por uma empresa privada do período de 1982 a 1995. Os resultados obtidos apresentaram evidências de relação negativa entre os gastos com educação e saúde e a percepção de corrupção. $\mathrm{O}$ autor sugere que agentes corruptos procuram coletar suborno da forma mais simples possível. Assim, áreas como a educação básica não seriam tão atrativas, pois seus insumos são fornecidos por grande número de empresas e não há necessidade de elevados investimentos em tecnologia (Mauro, 1998).

Gupta e colaboradores (2001) buscaram encontrar evidências da associação entre corrupção e gastos militares, examinando dados de 120 países e índices de percepção de corrupção. Duas hipóteses foram testadas envolvendo as relações entre corrupção e a proporção das 
despesas militares totais em relação ao PIB e a proporção das aquisições de equipamentos militares em relação ao PIB. Os resultados encontrados pelos autores indicaram que países com maiores níveis de corrupção tendem a apresentar maiores gastos militares.

No Brasil, Albuquerque e Ramos (2006) investigaram os determinantes da corrupção no nível municipal, utilizando um banco de dados construído pelos autores a partir dos relatórios originais do Programa Fiscalização de Municípios por meio de Sorteios Públicos, realizado pela Controladoria-Geral da União (CGU). Esse conjunto de dados reúne informações a respeito das irregularidades cometidas pelos administradores das transferências federais nos municípios. Os resultados obtidos pelos autores sugerem que os indivíduos estão mais inclinados a ser corruptos quando se defrontam com uma combinação envolvendo menores salários e maior poder discricionário. Ainda, a possibilidade de reeleição funciona como restrição à corrupção no primeiro mandato, sugerindo que os prefeitos se preocupam com seus ganhos futuros.

Ferraz e Finan (2008) estudaram os efeitos da divulgação de práticas corruptas verificadas nos governos locais nos resultados das eleições municipais no Brasil. Os autores analisaram o conteúdo dos Relatórios de Auditoria da Controladoria-Geral da União de 373 municípios e classificaram as irregularidades identificadas nos relatórios em três categorias: corrupção, má gestão e sem irregularidade. Os autores incluíram na categoria corrupção as práticas de superfaturamento, licitação com desvio de recurso e desvio de recursos, e observaram que, quanto maior o número de violações encontradas nas auditorias e divulgadas ao grande público, menor a probabilidade de o prefeito ser reeleito. Os autores concluem que os eleitores não apenas se preocupam com a corrupção, mas, de posse das informações relevantes, eles atualizam suas crenças a respeito da idoneidade do candidato e punem os prefeitos corruptos por meio do voto.

Sodré e Alves (2010) investigaram a relação entre emendas parlamentares ao orçamento e corrupção no âmbito municipal. Os autores argumentam que um dos determinantes da corrupção é a ocorrência de transferências de recursos financeiros federais na forma de emendas parlamentares sem o devido controle sobre sua gestão. As evidências encontradas sugerem a existência de relação entre transferências intergovernamentais por emendas parlamentares e corrupção, pois os municípios que receberam recursos de emendas parlamentares apresentaram, em média, 25\% mais episódios de corrupção. Os autores ressaltam que o aumento da corrupção parece estar mais relacionado com o fato de um município receber alguma emenda do que com o valor total das emendas recebidas.

Ferraz, Finan e Moreira (2012) sugerem que o desvio de verbas por corrupção resulta em perda da qualidade da educação oferecida aos cidadãos. Usando dados de corrupção na educação e de resultados acadêmicos de alunos de escolas públicas no Brasil, os autores encontraram que o desempenho dos alunos em exames padronizados foi significativamente menor em municípios com maiores taxas de corrupção. Adicionalmente, os autores encontraram efeitos da corrupção reduzindo o serviço efetivamente oferecido pelo governo, pois nos municípios com maior incidência de corrupção as escolas têm infraestrutura pior, os professores recebem menos treinamento e relatam maior preocupação com a falta de recursos. 
Bologna e Ross (2015) examinaram o efeito da corrupção na atividade econômica privada nos municípios brasileiros. Os autores construíram medidas de corrupção baseadas nos dados das auditorias realizadas pela Controladoria-Geral da União, e observaram que elevados níveis de corrupção reduzem o número de empresas operando em uma dada região, e esse efeito é mais forte com o passar do tempo, sugerindo que a corrupção é mais danosa à atividade econômica no longo prazo.

Observa-se na literatura desenvolvida com dados brasileiros que não foram desenvolvidos estudos a respeito da relação entre o nível de corrupção e a composição dos gastos, objetivo do presente estudo. Na próxima seção será apresentada a sustentação teórica que motiva a investigação a respeito da relação entre corrupção e composição do gasto público.

\section{Referencial teórico e desenvolvimento de hipóteses}

A definição precisa de corrupção não é consenso na literatura. Rose-Ackerman (2002:59) aponta que os incentivos ao suborno são criados "sempre que uma autoridade pública possui poder discricionário sobre a distribuição de um benefício ou de um custo para o setor privado".

Lambsdorff (2002) argumenta que a corrupção pode ser definida como o conluio de um agente com uma terceira parte com o intuito de violar as regras estabelecidas pelo principal para obter benefícios privados. O autor destaca que essa definição de corrupção assume a existência de um principal benevolente, que tem pleno controle sobre o sistema legal e sobre as recompensas e penalidades. Consequentemente, a definição está associada ao uso do framework da teoria de agência para entender a corrupção.

Entretanto, não há sustentação teórica e nem empírica para a afirmação de que aqueles que estão em posição de alterar o ambiente institucional são imunes à corrupção. Assim, se o principal não é benevolente, a definição de corrupção como a violação das regras é enganosa, e a abordagem da teoria de agência aplicada à corrupção terá seu poder explicativo reduzido.

Teorias para a corrupção baseadas na noção do principal não benevolente são mais céticas a respeito das motivações dos funcionários públicos, e partem da premissa de que todos os agentes, tanto burocratas como políticos, são corruptíveis (Aidt, 2003). O autor enfatiza que isso implica dizer que as instituições e políticas vigentes em um dado momento são altamente disfuncionais e ineficientes, pois não há um principal benevolente que projeta instituições e políticas ótimas.

Na perspectiva do principal não benevolente, Jain (2001) sugere definir a corrupção como um ato no qual o poder de um funcionário público é usado para obtenção de ganhos pessoais de um modo que viole as regras do jogo. Para que a corrupção ocorra de modo persistente, são necessárias três condições (Aidt, 2003):

(1) Poder discricionário: o funcionário público em questão deve possuir autoridade para projetar ou administrar políticas e regulações de maneira discricionária.

(2) Renda econômica: o poder discricionário deve permitir ao funcionário a extração da renda econômica existente, ou a criação de renda que possa ser extraída. 
(3) Instituições fracas: os incentivos oriundos das instituições políticas, administrativas e legais devem ser tais que os funcionários públicos experimentam incentivos para explorar o seu poder discricionário para extrair ou criar renda.

A rent-seeking theory tem sido sugerida como abordagem teórica que considera as várias formas pelas quais os agentes privados podem buscar tratamento preferencial junto aos tomadores de decisão na esfera do poder público (Lambsdorff, 2002). A corrupção é vista nessa abordagem como um tipo particular de atividade visando à captura de renda, sendo o lobby outro tipo. A distinção entre lobby e corrupção se dá pela forma como as decisões do governo são influenciadas (Lambsdorff, 2002). Se ocorrer um pagamento em dinheiro diretamente ao político ou ao funcionário público, então esse é um caso de corrupção. Mas não seria corrupção quando as decisões do governo são influenciadas por campanhas políticas, advogados, agência de relações públicas ou campanhas publicitárias.

A abordagem da rent-seeking theory adiciona uma dimensão à competição usual de mercado: a capacidade das empresas em usar a intervenção do Estado a seu favor. O Estado pode ser o fornecedor de fatores financeiros ou físicos, como no caso de subsídios e licenças, mas pode também demandar o produto das firmas, como no caso das compras públicas. Independente do caso, as ações do Estado frequentemente resultam em escassez, distúrbios no mercado ou preços que se desviam dos preços competitivos (Lambsdorff, 2002). O autor destaca que tais fenômenos induzem disputa sobre a renda criada e incentiva as empresas a competir por tratamento preferencial, de modo que a maximização do bem-estar social deixa de ser o objetivo do Estado.

Os agentes públicos podem receber subornos para beneficiar grupos de interesses ou empresas que competem por rendas criadas pela atuação do governo quando esse compra produtos ou serviços, impõe restrições à importação de produtos, cria taxas de importação para empresas concorrentes de outros países, cria subsídios e destina recursos para projetos inadequados, impondo custos desnecessários a toda a sociedade (Tullock, 1967; Kruger, 1974).

A abordagem da rent-seeking theory foi adaptada no presente estudo para desenvolver hipóteses relacionadas com a composição dos gastos municipais no Brasil nas três áreas que concentram o maior volume de recursos: educação, saúde e assistência social. Foram construídas seis hipóteses que analisaram a relação entre corrupção e composição dos gastos municipais sob duas óticas: a) recursos para educação, saúde e assistência social registrados nos orçamentos municipais; b) recursos para educação, saúde e assistência social originados de transferências da União para os municípios.

As hipóteses de 1 a 4 foram elaboradas com base na teoria, porém adaptada às particularidades da legislação brasileira. Assim, propõe-se no presente estudo que a relação entre corrupção e gastos municipais é contrária à desenvolvida no estudo de Mauro (1998). O autor sugeriu a existência de associação negativa entre os gastos de países com educação e saúde e o nível de corrupção. Os agentes públicos, influenciados pelos rent-seekers, direcionam recursos orçamentários para grupos de despesa nos quais os desvios podem ser realizados de forma mais fácil, reduzindo assim os gastos em saúde e educação. 
Se a dinâmica dos municípios brasileira fosse semelhante ao caso dos países analisados por Mauro (1998), seria lógico esperar que os grupos de despesas saúde e educação apresentassem pouca atratividade para os agentes corruptos, pois seus insumos geralmente podem ser adquiridos de um grande número de fornecedores e não envolvem alta tecnologia. No entanto, conforme exposto na seção 2.2, os municípios são obrigados a alocar no mínimo 40\% das receitas e transferências em saúde e educação, tornando essas as duas funções principais na administração pública municipal brasileira. Adicionalmente, a Lei de Responsabilidade Fiscal limita o gasto com pessoal. Assim, sugere-se que no Brasil os municípios com maiores níveis de corrupção irão apresentar maior alocação de despesas nas funções educação e saúde. Formalmente:

Hipótese 1 (H1): O nível de corrupção de um município na educação está associado positivamente às despesas em educação, no orçamento municipal.

Hipótese 2 (H2): O nível de corrupção de um município em saúde está associado positivamente às despesas em saúde, no orçamento municipal.

A elaboração das hipóteses 3 e 4 considerou novamente a existência de legislação específica do Brasil que obriga os municípios a aplicarem um percentual fixo de seus recursos em educação e saúde. Ainda, a legislação prevê que as transferências, tanto dos estados quanto da União (inclusive o Fundo de Participação dos Municípios), também devem ser levadas em conta no cálculo dos recursos totais do município, e não somente as receitas diretas municipais. Assim, espera-se uma relação positiva entre as transferências da União aos municípios, direcionadas às funções educação e saúde, e o nível de corrupção observado. Formalmente:

Hipótese 3 (H3): O nível de corrupção de um município em educação está associado positivamente às despesas do município em educação, originadas de Transferências da União.

Hipótese 4 (H4): O nível de corrupção de um município em saúde está associado positivamente às despesas do município em saúde, originadas de Transferências da União.

As hipóteses 5 e 6 tratam da avaliação da possível influência da corrupção sobre as despesas com assistência social. Os argumentos de Mauro (1998), baseados na rent-seeking theory, são no sentido de pouco interesse dos agentes corruptos por esse grupo de despesa, pois os limites ao valor das pensões resultam em maior dificuldade para extração de renda. Assim, espera-se uma associação negativa entre esse grupo de despesas e o nível de corrupção nos municípios brasileiros, pois tais limites se aplicam tanto nos gastos originados de Transferências da União quanto nos recursos do orçamento municipal (aposentadorias e pensões). Desse modo, as hipóteses são formuladas como:

Hipótese 5 (H5): O nível de corrupção de um município em assistência social é associado negativamente às despesas com assistência social, no orçamento do município.

Hipótese 6 (H6): O nível de corrupção de um município em assistência social é associado negativamente às despesas com assistência social, originadas de Transferências da União.

\section{Dados e amostra}

O presente estudo foi desenvolvido a partir de quatro fontes de dados distintas. A primeira, disponibilizada pela Controladoria-Geral da União, é composta por informações de- 
talhadas das constatações registradas pelos auditores da CGU nas auditorias e fiscalizações de 840 municípios no âmbito do Programa de Fiscalização por Sorteios Públicos da CGU, do $20^{\circ}$ ao $33^{\circ}$ sorteios, realizados entre 2006 e 2010. A segunda, com dados relativos às Transferências de Recursos da União, foi obtida no Portal da Transparência do Governo Federal, compreendendo o período de 2005 a 2010. A terceira foi baseada em dados contábeis das despesas dos municípios, de 2005 a 2010, classificadas por função de governo, obtidas na base de dados da série "Finanças do Brasil - Dados Contábeis dos Municípios", da STN. As transferências e as despesas municipais foram transformadas em preços constantes de 2000, tendo sido deflacionadas pelo IPCA. Por fim, os dados socioeconômicos municipais foram extraídos dos sistemas de divulgação de informações estatísticas do IBGE e do IPEA. O PIB per capita também está aos preços constantes de 2000.

Os valores das despesas e transferências de cada município da amostra são a preços constantes de 2000 e relativos aos anos $t$ e $t-1$, em que $t$ indica o ano da fiscalização do município no Programa de Fiscalização por Sorteios Públicos da CGU. Portanto, quando forem divididos pelo PIB, esses valores também são divididos pela soma dos PIBs dos anos $t$ e $t-1$. Nesse caso, deve-se destacar que o período de mensuração da corrupção refere-se ao ano anterior ao da coleta de dados sobre os gastos e transferências públicas. Esse é o mesmo critério utilizado por Sodré e Alves (2010) para relacionar as informações de constatações de fiscalização com as informações de transferências de recursos para os municípios fiscalizados.

\subsection{Mensuração da corrupção a partir de Relatórios de Auditoria e Fiscalizações da CGU}

Um grande desafio nas pesquisas sobre o fenômeno da corrupção é a sua mensuração, pois ela ocorre de forma clandestina, sem conhecimento do público e com a intenção de não deixar registros (Jain, 2001). Os pesquisadores têm buscado desenvolver parâmetros mais objetivos para medir corrupção, tais como casos de condenação judicial por corrupção (Glaeser e Saks, 2006) e irregularidades registradas em relatórios de auditoria (Albuquerque e Ramos, 2006; Ferraz e Finan, 2008; Ferraz, Finan e Moreira, 2012; Sodré e Alves, 2010).

O banco de dados com informações do Programa de Fiscalização por Sorteios Públicos (PFSP), disponibilizado pela CGU, traz originalmente informações detalhadas de 23.327 Ordens de Serviço (OS). Em cada OS os auditores registram, em uma "constatação", os problemas encontrados em relação aos objetos fiscalizados. No banco de dados do PFSP estão registradas 84.405 constatações. Cada OS pode conter mais de um registro de constatação, ou seja, uma OS para a análise de um Convênio firmado pela União com um município pode gerar várias constatações, como desvio de recursos, direcionamento de licitação, fraude etc.

Além do número da OS e do número da constatação, o banco de dados disponibilizado pela CGU contém a situação da OS, a classificação da constatação, a unidade auditada, o órgão federal responsável pelo repasse, os montantes envolvidos, o ano do repasse dos recursos, a classificação funcional-programática do gasto e uma descrição sumária da constatação. 
As constatações de fiscalização são classificadas pelos auditores da CGU de acordo com sua gravidade em: informação e comentários, falhas formais, falhas médias e falhas graves. Para o presente estudo foram considerados os dados de constatações relativos às classificações falhas médias e falhas graves. As constatações relativas ao programa Bolsa Família também foram retiradas da amostra, pois essas transferências são realizadas diretamente aos cidadãos e não transitam no orçamento municipal. Outros filtros foram aplicados nos registros da amostra original, com objetivo de excluir registros com omissões ou inconsistências.

O nível de corrupção municipal foi medido com base em uma adaptação da classificação proposta por Ferraz e Finan (2008), que dividiram as constatações em três grupos: corrupção, má gestão e sem irregularidade. No presente estudo, depois de identificadas as constatações classificadas como falhas médias e graves, disponíveis no banco de dados do PFSP da CGU, foi desenvolvido um procedimento para reclassificar as constatações como corrupção ou não. O procedimento aqui utilizado se fundamentou no uso de técnicas computacionais de text mining, ou mineração de texto, no campo "descrição sumária da constatação" do banco de dados do PFSP da CGU, de forma semelhante a Aguiar (2012).

O software Statistica 7 foi utilizado para realizar a etapa de tokenização, ou segmentação de palavras, definida por Palmer (2010) como a quebra de uma sequência de caracteres em um texto, localizando os limites da palavra, os pontos onde uma palavra termina e outra começa. A análise léxica também foi realizada com o software. Nessa fase as palavras já segmentadas foram reduzidas a seus radicais ou raiz, com base no dicionário lemma, processo denominado por Hippisley (2010:32) como stemming. O referido software também remove, nesse processo, as palavras comuns que não têm função textual relevante, como artigos, pronomes e alguns verbos.

Os radicais utilizados para identificar a incidência de corrupção foram selecionados com base nas irregularidades mais constatadas pela CGU (Brasil, 2003), tais como: obras inacabadas ou paralisadas; uso de notas fiscais frias; indícios de simulação de licitações; irregularidades no processo de licitações; empresas fantasmas; superfaturamento de preços etc. A lista de palavras cuja ocorrência sinaliza a existência de corrupção em uma constatação está disponível para consulta e pode ser solicitada aos autores.

Em seguida, os radicais de palavras relacionadas com a ocorrência de corrupção foram utilizados para reclassificar as constatações do banco de dados do Programa de Fiscalização por Sorteios Públicos da CGU. O nível de corrupção nas funções de governo de um município foi calculado pela divisão da quantidade de constatações reclassificadas como corrupção, em cada função de governo, pelo total de constatações registradas no banco de dados do PFSP da CGU, na mesma função de governo.

Desse modo, uma constatação, classificada na base da CGU como falha média ou grave, foi reclassificada no presente estudo como corrupção, caso tenha sido observada também a ocorrência de palavras-chave associadas à corrupção nas informações registradas pelos auditores da CGU na constatação. A tabela 3 exibe as quantidades de constatações registradas no banco de dados do PFSP, bem como todos os filtros que foram aplicados na amostra. 
Tabela 3

Amostra de constatações de fiscalização do PFSP (CGU)

\begin{tabular}{|lcc|}
\hline \multicolumn{1}{|c}{ Filtro para seleção de registros } & $\begin{array}{c}\text { Registros } \\
\text { Removidos }\end{array}$ & Amostra \\
\hline Amostra completa das constatações do PFSP de 2006 a 2012 & 84.405 \\
Constatações do PFSP de 2011 e 2012 & 16.586 & 67.819 \\
Constatações classificadas como "Falha Formal" & 3.469 & 64.350 \\
Constatações classificadas como "Informação ou Comentário" & 8.421 & 55.929 \\
Ordens de serviços não homologadas ou canceladas & 51 & 55.878 \\
Constatações canceladas ou não incluídas no relatório do PFSP & 2.884 & 52.994 \\
Constatações sem registro da classificação funcional-programática & 143 \\
Constatações em recursos orçamentários de anos anteriores ao exercício corrente ou anterior & 52.827 \\
à fiscalização & 7.202 \\
Constatações do programa Bolsa Família (transferência direta ao cidadão) & 4.106 \\
Amostra final de constatações do PFSP de 2006 a 2010 após aplicação dos filtros de seleção & 40.519 \\
de registros anteriormente descritos & 40.519 \\
\hline
\end{tabular}

Fonte: Elaborada pelos autores a partir do banco de dados do PFSP da CGU.

As constatações selecionadas no processo descrito resultaram em uma amostra de 840 municípios, dos quais 39 foram fiscalizados mais de uma vez.

\subsection{Modelos econométricos}

A base de dados construída conforme descrito nas seções anteriores resultou em um pool de cross-sections, ou agrupamento de dados transversais, em que cada observação corresponde a um município em determinado ano, mas não há observações repetidas de cada município em cada ano, o que impossibilita uma abordagem para dados em painel. Nesse caso, o método de mínimos quadrados ordinários é adequado, na medida em que os municípios são sorteados aleatoriamente e com reposição ao longo dos anos, conferindo independência entre as observações e eliminando correlações entre erros ao longo dos anos (Wooldridge, 2010).

A análise da associação entre corrupção e composição das despesas municipais e das transferências da União para municípios, de acordo com as hipóteses apresentadas, foi realizada por meio de dois modelos econométricos baseados nos estudos de Mauro (1998) e Gupta e colaboradores (2001). Cada modelo foi estimado utilizando-se os valores totais ou por função da variável dependente de interesse tal como descrito a seguir.

No primeiro modelo, a variável dependente é a despesa municipal, total ou de uma função de governo (assistência social, educação, saúde ou outras), em percentual do PIB municipal. A variável independente de interesse é o nível de corrupção (corrup) de um município 
$i$ que foi fiscalizado em determinado período de tempo $t$, em seu valor total ou na mesma função de governo (assistência social, educação, saúde e outras) da variável dependente.

As variáveis de controle selecionadas foram o índice de Gini (Gini), o produto interno bruto (PIB) do município, a população municipal (pop) e a taxa de urbanização (urban). Além dessas variáveis de controle, foi acrescentada no modelo (1) a variável "transferências sobre despesas", com o objetivo de controlar a representatividade das transferências da União nos orçamentos municipais e poder utilizar os níveis de corrupção apurados para as transferências da União como uma proxy para o nível de corrupção nas despesas municipais.

O segundo modelo foi empregado para analisar a relação entre corrupção e transferências da União para os municípios. A variável dependente é formada pelas transferências da União, em seu valor total ou em uma função de governo (assistência social, educação, saúde e outras), em percentual do PIB municipal. As variáveis independentes são idênticas às variáveis do modelo (1), com exceção da variável "transferências sobre despesas" que não foi incluída. Portanto, para cada uma das funções de governo e para o total de despesas/transferências, os seguintes modelos foram estimados por mínimos quadrados ordinários (MQO):

Desppib $_{i t}=\beta_{0}+\beta_{1}$ Corrup $_{i t}+\beta_{2}$ Gini $_{i t}+\beta_{3}$ Pib $_{i t}+\beta_{4}$ Pop $_{i t}+\beta_{5}$ Urban $_{i t}+\beta_{6}$ PTransf Desp $_{i t}+\varepsilon_{i t}$

Transfpib $_{i t}=\beta_{0}+\beta_{1}$ Corrup $_{i t}+\beta_{2}$ Gini $_{i t}+\beta_{3}$ Pib $_{i t}+\beta_{4}$ Pop $_{i t}+\beta_{5} \operatorname{Urban}_{i t}+\varepsilon_{i t}$

Em cada um dos modelos o objetivo é estimar o valor do parâmetro de interesse $\beta_{1}$, ou seja, inferir o efeito da corrupção na função (ou na totalidade) sobre a despesa (transferência) naquela função (ou totalidade). O sinal e a significância estatística das estimativas para o coeficiente serão usados para testar as hipóteses H1 a H6. O quadro 1 apresenta o detalhamento da construção das variáveis utilizadas nos modelos.

\section{Quadro 1}

Descrição da operacionalização das variáveis utilizadas nos modelos estatísticos

\begin{tabular}{|c|c|c|c|}
\hline Variável & $\begin{array}{l}\text { Código da } \\
\text { variável }\end{array}$ & Descrição & $\begin{array}{l}\text { Exemplos de estudos } \\
\text { que utilizaram a variável }\end{array}$ \\
\hline $\begin{array}{l}\text { Despesa } \\
\text { PIB }\end{array}$ & Desppib & $\begin{array}{l}\text { Despesas municipais, total ou em uma função de governo, } \\
\text { divididas pelo valor do PIB municipal. }\end{array}$ & Mauro (1998) \\
\hline $\begin{array}{l}\text { Transferências } \\
\text { PIB }\end{array}$ & TransfPib & $\begin{array}{l}\text { Transferências da União para um município, total ou em uma } \\
\text { função de governo, divididas pelo valor do PIB municipal. }\end{array}$ & Mauro (1998) \\
\hline Corrupção & Corrup & $\begin{array}{l}\text { Índice construído a partir das constatações de corrupção em um } \\
\text { município e em uma função de governo, divididas pelo total de } \\
\text { constatações de um município na mesma função de governo. }\end{array}$ & $\begin{array}{l}\text { Ferraz e Finan (2008), } \\
\text { Sodré e Alves (2010) }\end{array}$ \\
\hline Índice de Gini & Gini & Medida da desigualdade de renda e pobreza em um município & $\begin{array}{l}\text { Sodré e Alves (2010), } \\
\text { Albuquerque e Ramos } \\
\text { (2006) }\end{array}$ \\
\hline $\begin{array}{l}\text { PIB municipal } \\
\text { per capita }\end{array}$ & $\mathrm{PiB}$ & $\begin{array}{l}\text { Produto Interno Bruto municipal per capita em milhares de reais } \\
\text { (valores aos preços constantes de 2000) }\end{array}$ & Sodré e Alves (2010) \\
\hline
\end{tabular}

Continua 


\begin{tabular}{|c|c|c|c|}
\hline Variável & $\begin{array}{l}\text { Código da } \\
\text { variável }\end{array}$ & Descrição & $\begin{array}{l}\text { Exemplos de estudos } \\
\text { que utilizaram a variável }\end{array}$ \\
\hline População & Pop & População municipal em logaritmo & $\begin{array}{l}\text { Ferraz e Finan (2008), } \\
\text { Sodré e Alves (2010) }\end{array}$ \\
\hline $\begin{array}{c}\text { Taxa de } \\
\text { urbanização }\end{array}$ & Urban & Taxa de urbanização do município fiscalizado & Ferraz e Finan (2012) \\
\hline $\begin{array}{l}\text { Transferências } \\
\text { sobre despesa }\end{array}$ & PTransfdesp & \% transferências da União sobre despesas totais do município & - \\
\hline
\end{tabular}

Fonte: Elaborado pelos autores.

\section{Resultados e discussão}

\subsection{Estatística descritiva}

A tabela 4 apresenta as estatísticas descritivas das variáveis utilizadas no estudo. Observa-se que, em média, as transferências corresponderam a cerca de $60 \%$ das despesas dos municípios nos anos analisados. Os municípios estudados possuem um coeficiente de Gini médio de 0,39, uma renda per capita de $\mathrm{R} \$ 4.476$, em valores de 2000 , uma população de aproximadamente 12.700 habitantes e uma taxa de urbanização de $62,33 \%$.

As medidas de corrupção apresentadas na tabela 4 representam o percentual de constatações classificadas como corrupção, entre o total de constatações das auditorias. Em média, $15,65 \%$ das ordens de serviço foram classificadas como corruptas. Observa-se também que o percentual de constatações classificadas como corrupção é maior nas funções educação $(17,54 \%)$ e saúde $(18,94 \%)$ em relação a assistência social $(1,25 \%)$ e outras funções $(6,56 \%)$.

Tabela 4

Estatísticas descritivas da amostra

\begin{tabular}{|lccccc|}
\hline & Amostra & Média & Mínimo & Máximo & Desvio-padrão \\
\hline Transferências da União para os municípios & & & & & \\
Transferências para assistência social (1) (2) & 840 & 0,00 & 0,00 & 0,05 & 0,00 \\
Transferências para educação (2) & 840 & 0,03 & 0,00 & 0,18 & 0,03 \\
Transferências para saúde (2) & 840 & 0,02 & 0,00 & 0,09 & 0,01 \\
Transferências outras (2) & 840 & 0,10 & 0,00 & 0,60 & 0,07 \\
Transferências (2) & 840 & 0,15 & 0,00 & 0,73 & 0,11 \\
Despesas dos municípios & & & & & \\
Despesas com assistência social (2) & 760 & 0,01 & 0,00 & 0,10 & 0,01 \\
\hline
\end{tabular}




\begin{tabular}{|c|c|c|c|c|c|}
\hline & Amostra & Média & Mínimo & Máximo & Desvio-padrão \\
\hline Despesas com educação (2) & 762 & 0,07 & 0,01 & 0,23 & 0,04 \\
\hline Despesas com saúde (2) & 760 & 0,05 & 0,00 & 0,17 & 0,03 \\
\hline Despesas em outras funções (2) & 760 & 0,10 & 0,02 & 0,42 & 0,05 \\
\hline Despesas (2) & 762 & 0,22 & 0,04 & 0,80 & 0,12 \\
\hline Transferências sobre despesas (\%) & 762 & 0,60 & 0,05 & 0,98 & 0,17 \\
\hline \multicolumn{6}{|l|}{ Dados socioeconômicos dos municípios } \\
\hline Índice de Gini & 836 & 0,39 & 0,29 & 0,51 & 0,03 \\
\hline PIB per capita (milhares de reais) & 840 & 4,48 & 1,01 & 48,62 & 4,02 \\
\hline População municipal (logaritmo) & 840 & 9,45 & 6,72 & 13,14 & 1,11 \\
\hline Taxa de urbanização (\%) & 840 & 62,33 & 4,18 & 100,00 & 22,05 \\
\hline \multicolumn{6}{|l|}{ Corrupção em municípios brasileiros } \\
\hline Corrupção em assistência social (1) (3) & 775 & 1,25 & 0,02 & 16,29 & 1,94 \\
\hline Corrupção em educação (3) & 817 & 17,54 & 0,00 & 100,00 & 15,02 \\
\hline Corrupção em saúde (3) & 824 & 18,94 & 0,00 & 100,00 & 13,86 \\
\hline Corrupção em outras funções (3) & 754 & 6,56 & 0,00 & 100,00 & 12,00 \\
\hline Corrupção (1) (3) & 840 & 15,65 & 0,00 & 65,71 & 9,17 \\
\hline
\end{tabular}

Fonte: Elaborada pelos autores com base em: Transferências da União: dados da CGU disponíveis no Portal da Transparência do Governo Federal: <www.portaldatransparencia.gov.br>. Acesso em: 3 abr. 2013; Despesas municipais: dados da STN disponíveis em: <www.tesouro.fazenda.gov.br/pt/prefeituras-governos-estaduais/sobre>. Acesso em: 27 mar. 2013; Índice de Gini: IBGE, Censo Demográfico 2000 e Pesquisa de Orçamentos Familiares - POF 2002/2003: <www.cidades.ibge.gov.br/>. Acesso em: 4 abr. 2013; PIB municipal: <www. ipeadata.gov.br/>. Acesso em: 27 mar. 2013; População: <www.ipeadata.gov.br>. Acesso em: 27 mar. 2013; Taxa de urbanização: IBGE, Censo demográfico 2010: <www.ibge.gov.br>. Acesso em: 4 abr. 2013; Corrupção: dados do PFSP da CGU.

Notas: (1) Não inclui as transferências relacionadas com o "Programa Bolsa Família"; (2) Em percentual do PIB municipal; (3) em percentual, calculado pela divisão das constatações classificadas como corrupção pelo total de constatações registradas no banco de dados do PFSP da CGU.

\subsection{Resultados da análise da associação entre corrupção e despesas municipais}

A análise da relação entre corrupção e composição das despesas municipais com base no modelo de regressão (1) foi desenvolvida com o objetivo de avaliar as hipóteses H1, H2 e H5 do presente estudo. A tabela 5 apresenta os resultados da estimação por mínimos quadrados ordinários, referente ao modelo (1), com todas as variáveis de controle utilizadas para ajustar outros efeitos já conhecidos que podem afetar o nível de corrupção (Albuquerque e Ramos, 2006; Ferraz e Finan, 2008; Sodré e Alves, 2010; Ferraz, Finan e Moreira, 2012). 
Tabela 5

\section{Resultados da regressão múltipla - modelo (1) - despesas municipais}

\begin{tabular}{|c|c|c|c|c|c|}
\hline \multirow[b]{2}{*}{ Variáveis dependentes } & \multicolumn{5}{|c|}{ Despesas em percentual ao PIB municipal } \\
\hline & $\begin{array}{l}\text { Assistência } \\
\text { Social (a) }\end{array}$ & Educação & Saúde & $\begin{array}{c}\text { Outras } \\
\text { Despesas }\end{array}$ & $\begin{array}{c}\text { Despesas } \\
\text { Totais }\end{array}$ \\
\hline \multirow{2}{*}{ Corrupção (a) } & $-0,0004^{* * *}$ & $0,0002 * * *$ & $0,0003^{* * *}$ & $0,0002^{*}$ & $0,0017^{* * *}$ \\
\hline & $(0,0001)$ & $(0,00007)$ & $(0,00006)$ & $(0,0001)$ & $(0,0003)$ \\
\hline \multirow{2}{*}{ Índice de Gini } & 0,009 & $-0,0987 * *$ & $-0,0052$ & $-0,0750$ & $-0,1650$ \\
\hline & $(0,009)$ & $(0,0445)$ & $(0,0261)$ & $(0,0560)$ & $(0,1102)$ \\
\hline \multirow{2}{*}{ PIB municipal per capita } & $-3,37 e-07^{* *}$ & $-3,06 e-06 * * *$ & $-1,97 e-06^{* * *}$ & $-5,09 e-06^{* * *}$ & $-9,15 e-06^{* * *}$ \\
\hline & $(1,37 e-07)$ & $(8,25 e-07)$ & $(5,41 e-07)$ & $(7,85 e-07)$ & $(2,34 \mathrm{e}-06)$ \\
\hline \multirow{2}{*}{ População } & $-0,0024^{* * *}$ & $-0,0024 *$ & $-0,0053^{* * *}$ & $-0,0222^{* * *}$ & $-0,0296 * * *$ \\
\hline & $(0,0003)$ & $(0,0013)$ & $(0,0009)$ & $(0,0018)$ & $(0,0034)$ \\
\hline \multirow{2}{*}{ Taxa de urbanização } & 0,00002 & $-0,0004 * * *$ & $-4,36 e-06$ & 0,00007 & $-0,0003^{*}$ \\
\hline & $(0,00002)$ & $(0,00007)$ & $(0,00004)$ & $(0,00008)$ & $(0,0002)$ \\
\hline \multirow{2}{*}{ Transferências sobre despesa } & $0,0176^{* * *}$ & $0,0942 * * *$ & $0,0587^{* * *}$ & $0,0634^{* * *}$ & $0,2110^{* * *}$ \\
\hline & $(0,0031)$ & $(0,01133)$ & $(0,0072)$ & $(0,0163)$ & $(0,0322)$ \\
\hline \multirow{2}{*}{ Constante } & $0,0186^{* * *}$ & $0,0651^{* * *}$ & $0,0697^{* * *}$ & $0,3146^{* * *}$ & $0,4758^{* * *}$ \\
\hline & $(0,0046)$ & $(0,0248)$ & $(0,0147)$ & $(0,0319)$ & $(0,0660)$ \\
\hline Amostra & 699 & 737 & 741 & 680 & 758 \\
\hline Estatística F & 28,80 & 100,08 & 92,23 & 69,73 & 102,42 \\
\hline Significância modelo & 0,00 & 0,00 & 0,00 & 0,00 & 0,00 \\
\hline $\mathrm{R}^{2}$ & 0,31 & 0,52 & 0,51 & 0,48 & 0,55 \\
\hline $\mathrm{R}^{2}$ ajustado & 0,30 & 0,51 & 0,50 & 0,47 & 0,55 \\
\hline
\end{tabular}

Fonte: Elaborada pelos autores com base em: dados de corrupção foram obtidos a partir do banco de dados do PFSP da CGU; despesas municipais obtidas a partir dos dados da STN base "Finbra" disponíveis em: <www.tesouro.fazenda.gov.br/pt/prefeituras-governos-estaduais/sobre>. Acesso em: 27 mar. 2013; Índice de Gini: IBGE, Censo Demográfico 2000 e Pesquisa de Orçamentos Familiares - POF 2002/2003: <www.cidades.ibge.gov.br>. Acesso em: 4 abr. 2013; PIB municipal: <www.ipeadata.gov.br>. Acesso em: 27 mar. 2013 ; População: <www.ipeadata.gov.br>. Acesso em: 27 mar. 2013; Taxa de urbanização: IBGE, Censo demográfico 2010: <www.ibge.gov. br>. Acesso em: 4 abr. 2013.

Notas: Entre parênteses está o erro-padrão robusto, a heterocedasticidade e autocorrelação. * significativo a 10\%; ** significativo a 5\%; *** significativo a 1\%; (a) Não inclui as informações de constatações e transferências do "Programa Bolsa Família".

Conforme observado nas últimas três linhas da tabela 5 , os resultados sinalizam um bom ajuste dos modelos desenvolvidos, de acordo com a estatística $F$ e o $R^{2}$ ajustado. Os modelos de regressão são significativos a $1 \%$ e o menor $R^{2}$ ajustado observado é de 0,31 . 
Observa-se também, na última coluna da tabela 5 , que o coeficiente estimado para a variável independente corrupção $(\beta=0,0017$, p-valor $<0,01)$ indica uma associação positiva entre a ocorrência de corrupção em um município e suas despesas totais em percentual do PIB.

As duas primeiras linhas da tabela 5 também indicam a existência de associação estatisticamente significante a 1\% entre corrupção e as despesas das funções assistência social, educação e saúde. Conforme esperado, os resultados obtidos para a associação entre corrupção e as despesas nas funções educação e saúde são divergentes dos obtidos por Mauro (1998), porém consistentes com as hipóteses desenvolvidas.

Os sinais encontrados para os coeficientes que relacionam a corrupção na função com as despesas na mesma função são consistentes com as hipóteses H1, H2 e H5, conforme mostram os valores 0,0002, 0,0003 e 0,0004, respectivamente. Os resultados sugerem que os municípios com maiores níveis de corrupção alocam mais recursos, em relação ao PIB, nos gastos em educação e saúde e menos com assistência social.

A relação negativa observada entre corrupção e despesas na função assistência social está alinhada com os argumentos de Mauro (1998) quanto ao baixo interesse de rent-seekers por esse grupo de despesa, pois as rendas obtidas por transação são limitadas ao valor das pensões ou benefícios sociais.

\subsection{Resultados dos modelos de regressão para análise da relação entre corrupção e transferências da União aos municípios}

Para a avaliar H3, H4 e H6 do presente estudo foi desenvolvida a análise de cinco equações de regressão múltipla, agrupadas na descrição do modelo (2), transferências da União para municípios, em percentual do PIB municipal. A tabela 6 apresenta os resultados da estimativa por mínimos quadrados ordinários para tais modelos.

Tabela 6

Resultados da regressão múltipla - modelo (2) - transferências da União aos municípios

\begin{tabular}{|c|c|c|c|c|c|}
\hline \multirow[b]{2}{*}{$\begin{array}{c}\text { Variáveis } \\
\text { dependentes }\end{array}$} & \multicolumn{5}{|c|}{ Transferências em percentual do PIB municipal } \\
\hline & $\begin{array}{l}\text { Assistência Social } \\
\text { (a) }\end{array}$ & Educação & Saúde & $\begin{array}{c}\text { Outras } \\
\text { Transferências }\end{array}$ & $\begin{array}{c}\text { Transferências } \\
\text { Totais }\end{array}$ \\
\hline \multirow{2}{*}{ Corrupção } & $-0,0002 * * *$ & $0,0004^{* * *}$ & $0,0002^{* * *}$ & 0,0001 & $0,0024 * * *$ \\
\hline & $(0,0001)$ & $(0,0001)$ & $(0,0001)$ & $(0,0001)$ & $(0,0003)$ \\
\hline \multirow{2}{*}{ Índice de Gini } & $-0,0017$ & $-0,1871^{* * *}$ & $-0,0139$ & $-0,2206 * * *$ & $-0,3888 * * *$ \\
\hline & $(0,0035)$ & $(0,0306)$ & $(0,0146)$ & $(0,0680)$ & $(0,0895)$ \\
\hline \multirow{2}{*}{$\begin{array}{l}\text { PIB municipal } \\
\text { per capita }\end{array}$} & $-3,43 e-07^{* * *}$ & $-3,10 \mathrm{e}-06^{* * *}$ & $-1,72 \mathrm{e}-06^{* * *}$ & $-9,59 \mathrm{e}-06^{* * *}$ & $-0,0001^{* * *}$ \\
\hline & $(6,73 e-08)$ & $(5,31 e-07)$ & $(2,88 e-07)$ & $(1,10 e-06)$ & $(2,04 \mathrm{e}-06)$ \\
\hline
\end{tabular}




\begin{tabular}{|c|c|c|c|c|c|}
\hline \multirow[b]{2}{*}{$\begin{array}{c}\text { Variáveis } \\
\text { dependentes }\end{array}$} & \multicolumn{5}{|c|}{ Transferências em percentual do PIB municipal } \\
\hline & $\begin{array}{l}\text { Assistência Social } \\
\text { (a) }\end{array}$ & Educação & Saúde & $\begin{array}{c}\text { Outras } \\
\text { Transferências }\end{array}$ & $\begin{array}{c}\text { Transferências } \\
\text { Totais }\end{array}$ \\
\hline \multirow{2}{*}{ População } & $-0,0005^{* * *}$ & $0,0060^{* * *}$ & $0,0012^{* * *}$ & $-0,0327^{* * *}$ & $-0,0292^{* * *}$ \\
\hline & $(0,0001)$ & $(0,0009)$ & $(0,0004)$ & $(0,0024)$ & $(0,0029)$ \\
\hline \multirow{2}{*}{$\begin{array}{l}\text { Taxa de } \\
\text { urbanização }\end{array}$} & $-0,0001^{* * *}$ & $-0,0004 * *$ & $-0,0001 * * *$ & $-0,0001$ & $-0,0006^{* * *}$ \\
\hline & $(6,07 e-06)$ & $(0,0001)$ & $(0,0001)$ & $(0,0001)$ & $(0,0001)$ \\
\hline \multirow{2}{*}{ Constante } & $0,0120^{* * *}$ & $0,0826^{* * *}$ & $0,0248 * * *$ & $0,5438 * * *$ & $0,6348^{* * *}$ \\
\hline & $(0,0019)$ & $(0,0115)$ & $(0,0060)$ & $(0,0339)$ & $(0,0433)$ \\
\hline Amostra & 775 & 813 & 820 & 750 & 836 \\
\hline Estatística F & 21,06 & 162,66 & 60,74 & 67,61 & 94,40 \\
\hline $\begin{array}{l}\text { Significância } \\
\text { modelo }\end{array}$ & 0,00 & 0,00 & 0,00 & 0,00 & 0,00 \\
\hline$R^{2}$ & 0,23 & 0,42 & 0,37 & 0,51 & 0,52 \\
\hline $\mathrm{R}^{2}$ ajustado & 0,23 & 0,41 & 0,36 & 0,50 & 0,51 \\
\hline
\end{tabular}

Fonte: Elaborada pelos autores com base em: dados de corrupção obtidos a partir do banco de dados do PFSP da CGU; Transferências da União para municípios foram obtidas no Portal da Transparência do Governo Federal: <www.portaldatransparencia.gov.br>. Acesso em: 3 abr. 2013; Índice de Gini: IBGE, Censo Demográfico 2000 e Pesquisa de Orçamentos Familiares - POF 2002/2003: <www.cidades. ibge.gov.br>. Acesso em: 4 abr. 2013; PIB municipal: <www.ipeadata.gov.br>. Acesso em: 27 mar. 2013; População: <www.ipeadata. gov.br>. Acesso em: 27 mar. 2013; Taxa de urbanização: IBGE, Censo demográfico 2010: <www.ibge.gov.br>. Acesso em: 4 abr. 2013. Notas: Entre parênteses está o erro-padrão robusto, a heterocedasticidade e autocorrelação. * significativo a 10\%; ** significativo a 5\%; *** significativo a 1\%; (a) Não inclui as informações de constatações e transferências do "Programa Bolsa Família".

Semelhante ao observado nos resultados obtidos com o modelo (1), as últimas três linhas da tabela 6 exibem indicadores de que a análise de regressão resultou em um bom ajuste do modelo aos dados, de acordo com a estatística $F$ e o $R^{2}$ ajustado, com os modelos se mostrando estatisticamente significantes a $1 \%$ e o $R^{2}$ ajustado mínimo de 0,23 . Complementarmente, na última coluna da tabela 6 , observa-se que o coeficiente estimado para a variável independente corrupção $(0,0024$, p-valor $<0,01)$ indica uma associação positiva entre a ocorrência de corrupção em um município e as transferências da União para o mesmo.

Adicionalmente, a tabela 6 exibe associação estatisticamente significante a 1\% entre corrupção e as transferências da União nas funções assistência social, educação e saúde. Em linha com as hipóteses H3, H4 e H6 desenvolvidas, os coeficientes estimados para as variáveis corrupção nas funções educação e saúde (0,0004, p-valor $<0,01 ; 0,0002$, p-valor $<0,01$, respectivamente) indicam que o aumento na corrupção nessas funções está associado a maiores transferências da União para a mesma função, de acordo com as hipóteses H3 e H4.

Tais resultados são contrários ao encontrados por Mauro (1998), que analisou os efeitos da corrupção no nível dos países. Adicionalmente, o coeficiente estimado para a variável corrupção na função assistência social $(-0,0002$, p-valor $<0,01)$ aponta para uma associação 
negativa entre a ocorrência de corrupção na função e o valor das transferências da União, de acordo com a hipótese H6 desenvolvida no presente estudo.

Em síntese, os resultados obtidos constituem indícios favoráveis às hipóteses teóricas desenvolvidas, mesmo que algumas delas tenham sido construídas de maneira inversa ao comumente encontrado na literatura, em virtude da influência esperada dos aspectos institucionais brasileiros.

\subsection{Testes de robustez}

Com o intuito de avaliar a robustez dos resultados apresentados nas seções 6.2 e 6.3, foram realizadas modificações nas especificações e na base de dados utilizadas no estudo. O primeiro teste consistiu em remover da amostra as 39 observações correspondentes a repetições de municípios. Esses municípios foram aleatoriamente sorteados mais de uma vez ao longo dos anos estudados. Os resultados para essa nova amostra permanecem inalterados em sua magnitude e significâncias estatísticas (ver apêndice, tabelas A e B). Conclui-se que as observações adicionais não comprometem a robustez das estimativas.

Um segundo teste foi feito substituindo-se a variável de normalização, buscando replicar uma especificação de Mauro (1998). Ao invés de utilizar as variáveis despesas e transferências por função como proporção do PIB, elas foram normalizadas pela despesa e transferências totais, respectivamente. Os resultados apontam que nesse caso os coeficientes para as funções assistência social e educação continuam significantes e com os sinais esperados, porém o coeficiente dos modelos para a função saúde deixa de ser estatisticamente significativo, apesar de manter o sinal (ver apêndice, tabelas C e D). A ausência de significância estatística parece estar relacionada com o fato de que a despesa com saúde como proporção do PIB e a despesa com saúde como proporção da despesa total possuem baixa correlação $(0,2854)$, enquanto essa correlação é mais alta para educação $(0,6336)$ e assistência social $(0,7278)$. A mesma situação ocorre com as transferências para saúde $(0,3478)$, educação $(0,8089)$ e assistência social $(0,6993)$. Portanto, os resultados do teste de robustez indicam que municípios mais corruptos não necessariamente realocam mais despesas e transferências para a saúde dado um nível total de despesas, mas que elevam as suas despesas totais como proporção do PIB (como visto nas seções 6.2 e 6.3) e direcionam parte desses novos recursos para a saúde.

\section{Conclusão}

Estudos empíricos anteriores compararam dados socioeconômicos e financeiros de países e índices de percepção de corrupção, e encontraram evidências das consequências econômicas e sociais negativas trazidas pela corrupção: menor crescimento econômico, baixo investimento, redução da eficiência, da justiça e da legitimidade das atividades do Estado. Outros estudos, usando dados brasileiros, analisaram causas e consequências da corrupção, influência 
da divulgação de ocorrências de corrupção no resultado de pleitos eleitorais, na qualidade dos serviços oferecidos pelo governo e na atividade econômica no setor privado. O presente estudo teve como objetivo analisar a relação entre corrupção e composição dos gastos governamentais nos municípios do Brasil. Como as análises foram direcionadas para o nível dos municípios, aspectos legais específicos precisaram ser levados em consideração.

Adicionalmente, o nível de corrupção municipal foi medido com base nas constatações de auditoria registradas nos relatórios da CGU no âmbito do Programa de Fiscalização por Sorteios Públicos. Foram utilizadas técnicas de mineração de texto para reclassificar as constatações de auditoria e identificar ocorrência de corrupção.

Os resultados obtidos sugerem que maiores níveis de corrupção nos municípios acarretam maiores despesas em funções de educação e saúde, às quais a própria legislação obriga percentuais elevados de despesa. Como resultado, aumenta o gasto público municipal total, porém sem a contraparte positiva para a sociedade. Uma explicação oferecida para os resultados é que a exigência legal cria incentivos para a atuação de rent-seekers, ou agentes corruptores que são atraídos pela maior disponibilidade de recursos.

As evidências encontradas no presente estudo sugerem que o modelo atual de distribuição, aplicação e controle de recursos públicos próprios ou transferidos do orçamento da União para os municípios brasileiros pode não estar adequado. Tal fato é agravado por dois motivos:

1) a recente aprovação da Proposta de Emenda à Constituição (PEC), que modifica normas de execução orçamentária e estabelece o chamado "Orçamento Impositivo" que torna obrigatória a liberação de verbas originadas das emendas parlamentares individuais, destinadas, em geral, a municípios e que aumentam em 25\% os episódios de corrupção, nos municípios beneficiados, conforme estudo de Sodré e Alves (2010);

2) a aprovação pelo Congresso Nacional da Lei no 12.858, de 9 de setembro de 2013, que dispõe sobre a destinação para as áreas de educação e saúde de royalties do petróleo dos campos da camada pré-sal descoberta na costa brasileira e amplia, segundo o governo federal, o montante de recursos públicos destinados a educação em 368 bilhões de reais, nos próximos 30 anos, recursos que serão transferidos em grande parte aos municípios brasileiros.

Medidas de prevenção e combate à corrupção, reconhecidas e recomendadas por organismos internacionais (ONU, OEA e Ocde), vêm sendo adotadas no âmbito do governo federal e na maioria dos estados brasileiros, tais como: ampliação da transparência e do acesso à informação, aumento da integridade nos órgãos públicos, criação e fortalecimento dos órgãos de controle interno, fomento da ética e do controle social, prevenção de conflito de interesses e punição para desvios de conduta. No entanto, parece ser necessário expandir as medidas anticorrupção reconhecidas internacionalmente aos entes municipais, inclusive com a implantação de mecanismos de avaliação e acompanhamento de sua implantação, que podem constituir um conjunto de medidas adequadas para fortalecer a integridade dos governos locais, reduzir a corrupção e aumentar a eficiência dos gastos públicos.

Por fim, novos estudos podem ser desenvolvidos para aperfeiçoar a mensuração do nível de corrupção municipal e identificar a ocorrência de outros efeitos econômicos e sociais 
desse fenômeno em municípios brasileiros. A análise dos relatórios de auditoria e fiscalizações realizadas pelos Tribunais de Contas Estaduais, juntamente com os relatórios do PFSP da CGU, possibilitaria uma visão global sobre o nível de corrupção de um município.

\section{Referências}

ADES, Alberto; DI TELLA, Rafael. Rents, competition, and corruption. American Economic Review, v. 89, n. 4, p. 982-993, 1999.

AGUIAR, Marcelo O. Sentiment analysis em relatórios da administração divulgados por firmas brasileiras. Dissertação (mestrado) - Fundação Instituto Capixaba de Pesquisas em Contabilidade, Economia e Finanças, Vitória, 2012.

AIDT, Toke S. Economic analysis of corruption - a survey. The Economic Journal, v. 113, n. 491, p. 632-652, 2003.

ALBUQUERQUE, Breno E.; RAMOS, Francisco S. Análise teórica e empírica dos determinantes de corrupção na gestão pública municipal. In: ENCONTRO NACIONAL DE ECONOMIA, XXXIV, ANPEC — ASSOCIAÇÃO NACIONAL DOS CENTROS DE PÓS-GRADUAÇÃO EM ECONOMIA, 2006. Anais... Disponível em: <www.anpec.org.br/encontro2006/artigos/A06A030.pdf>. Acesso em: 25 jan. 2013.

BARRO, Robert J. Economic growth in a cross section of countries. Quarterly Journal of Economics, v. 106, n. 2, p. 407-443, 1991.

BOLOGNA, Jamie; ROSS, Amanda. Corruption and entrepreneurship: evidence from a random audit program. West Virginia University Department of Economics Working Papers Series, 15-05, 2015. Disponível em: <www.be.wvu.edu/phd_economics/pdf/15-05.pdf>. Acesso em: 23 jun. 2015.

BRASIL. Ato das Disposições Constitucionais Transitórias. Brasília, DF: Senado Federal: Centro Gráfico, 1988b.

BRASIL. Constituição da República Federativa do Brasil. Brasília, DF: Senado Federal: Centro Gráfico, 1988a.

BRASIL. Controladoria-Geral da União. Relatório de gestão - exercício 2003, 2003. Disponível em: $<$ www.cgu.gov.br/Publicacoes/RelatGestao/Arquivos/relatorio_gestao_cgu_2003.pdf >. Acesso em: 19 mar. 2013.

BRASIL. Lei no 4.320 de 17 de março de 1964. Estatui normas de Direito Financeiro para elaboração e controle dos Orçamentos e Balanços da União, dos Estados, dos Municípios e do Distrito Federal. Disponível em: <www.planalto.gov.br/ccivil_03/leis/14320.htm>. Acesso em: 27 ago. 2013.

BRASIL. Ministério do Orçamento e Gestão (MOG). Portaria no 42, de 14 de abril de 1999. Atualiza a discriminação da despesa por funções de que tratam o inciso I do $\S 1^{\circ}$ do art. $2^{\circ}$ e $\S 2^{\circ}$ do art. $8^{\circ}$, ambos da Lei no 4.320, de 17 de março de 1964, estabelece os conceitos de função, subfunção, programa, projeto, atividade, operações especiais, e dá outras providências. Disponível em: <www3. tesouro.gov.br/legislacao/download/ contabilidade/portaria42.pdf>. Acesso em: 23 jun. 2015. 
FERRAZ, Claudio; FINAN, Frederico. Exposing corrupt policiticans: the effects of Brazil's publicily released audits on electoral outcomes. Quarterly Journal of Economics, v. 123, n. 2, p. 703-745, 2008. FERRAZ, Claudio; FINAN, Frederico; MOREIRA, Diana B. Corrupting learning: evidence from missing federal education funds in Brazil. Journal of Public Economics, v. 96, n. 9/10, p. 712-726, 2012. GLAESER, Edward L.; SAKS, Raven. Corruption in America. Journal of Public Economics, v. 90, n. 6/7, p. 1053-1073, 2006.

GUPTA, Sanjeev et al. Corruption and military spending. European Journal of Political Economy, v. 17, n. 4, p. 749-777, 2001.

HIPPISLEY, Andrew. Lexical analysis. In: INDURKHYA, Nitin; DAMERAU, Fred J. (Org.). Handbook of natural language processing. 2. ed. Flórida: CRC Press, 2010.

JAIN, Arvind K. Corruption: a review. Journal of Economic Survey, v. 15, n. 1, p. 71-121, 2001.

KRUEGER, Anne O. The political economy of the rent-seeking society. The American Economic Review, v. 64, n. 3, p. 291-303, 1974.

LAMBSDORFF, Johann Graf. Corruption and rent-seeking. Public Choice, v. 113, n. 1/2, p. 97-125, 2002.

MAURO, Paulo. Corruption and growth. Quarterly Journal of Economics, v. 110, n. 3, p. 681-712, 1995.

MAURO, Paulo. Corruption and the composition of government expenditure. Journal of Public Economics, v. 69, n. 2, p. 263-279, 1998.

OLKEN, Benjamin A. Corruption perceptions vs. corruption reality. Journal of Public Economics, v. 93, n. 7/8, p. 950-964, 2009.

PALMER, David. Text preprocessing. In: INDURKHYA, Nitin; DAMERAU Fred J. (Org.). Handbook of natural language processing. 2. ed. Flórida: CRC Press, 2010.

ROSE-ACKERMAN, Susan A. Economia política da corrupção. In: ELLIOT, Kimberly A. (Org.). A corrupção e a economia global. Brasília: UnB, 2002. p. 59-102.

SHLEIFER, Andrei; VISHNY, Robert W. Corruption. Quarterly Journal of Economics, v. 108, n. 3, p. 599-617, 1993.

SODRÉ, Antonio; ALVES, Maria. Relação entre emendas parlamentares e corrupção municipal no Brasil: estudo dos relatórios do programa de fiscalização da Controladoria-Geral da União. Revista de Administração Contemporânea, v. 14, n. 3, p. 414-433, 2010.

TANZI, Vito; DAVOODI, Hamid. Corruption, public investment, and growth. IMF Working Paper, 1997. Disponível em: <www.imf.org/external/pubs/ft/wp/wp97139.pdf>. Acesso em: 23 jun. 2015.

TULLOCK, Gordon. The welfare costs of tariffs, monopolies, and thef. Western Economic Journal, v. 5, n. 3, p. 224-232, 1967.

WOOLDRIDGE, Jeffrey. Introdução à econometria: uma abordagem moderna. São Paulo: Cengage Learning, 2010. 
Olavo Venturim Caldas é analista de finanças e controle na Secretaria de Transparência e Prevenção da Corrupção (STPC) na Controladoria-Geral da União (CGU).E-mail: olavo.caldas@cgu.gov.br.

Cristiano Machado Costa é professor assistente no Programa de Pós-Graduação em Ciências Contábeis da Universidade do Vale do Rio dos Sinos (Unisinos).E-mail: cristianocosta@unisinos.br.

Marcelo Sanches Pagliarussi é professor doutor no Departamento de Contabilidade da Faculdade de Economia, Administração e Contabilidade de Ribeirão Preto (FEA-RP). E-mail: marcelosp@usp.br.

\section{Apêndice}

Tabela A

\section{Resultados da regressão múltipla - modelo (1) - despesas municipais}

\begin{tabular}{|c|c|c|c|c|c|}
\hline \multirow[b]{2}{*}{ Variáveis dependentes } & \multicolumn{5}{|c|}{ Despesas em percentual ao PIB municipal } \\
\hline & $\begin{array}{c}\text { Assistência } \\
\text { Social (a) }\end{array}$ & Educação & Saúde & Outras Despesas & $\begin{array}{c}\text { Despesas } \\
\text { Totais }\end{array}$ \\
\hline Corrupção (a) & $\begin{array}{c}-0,0004^{* * *} \\
(0,0001)\end{array}$ & $\begin{array}{l}0,0002^{* * *} \\
(0,00007)\end{array}$ & $\begin{array}{l}0,0002^{* * *} \\
(0,00006)\end{array}$ & $\begin{array}{c}0,0001 \\
(0,0001)\end{array}$ & $\begin{array}{l}0,0016^{* * *} \\
(0,0003)\end{array}$ \\
\hline Índice de Gini & $\begin{array}{c}0,0090 \\
(0,0096)\end{array}$ & $\begin{array}{l}-0,1011^{* *} \\
(0,0458)\end{array}$ & $\begin{array}{l}-0,0062 \\
(0,0268)\end{array}$ & $\begin{array}{l}-0,0903 \\
(0,0554)\end{array}$ & $\begin{array}{l}-0,1762 \\
(0,1132)\end{array}$ \\
\hline PIB municipal per capita & $\begin{array}{c}-3,38 \mathrm{e}-07^{* *} \\
(1,62 \mathrm{e}-07)\end{array}$ & $\begin{array}{c}-3,08 \mathrm{e}-06^{* * *} \\
(9,57 \mathrm{e}-07)\end{array}$ & $\begin{array}{c}-2,06 \mathrm{e}-06^{* * *} \\
(6,48 \mathrm{e}-07)\end{array}$ & $\begin{array}{c}-5,74 \mathrm{e}-06^{* * *} \\
(7,55 \mathrm{e}-07)\end{array}$ & $\begin{array}{c}-9,60 \mathrm{e}-06^{* * *} \\
(2,73 \mathrm{e}-06)\end{array}$ \\
\hline População & $\begin{array}{c}-0,0024^{* * *} \\
(0,0003)\end{array}$ & $\begin{array}{l}0,0027^{*} \\
(0,0014)\end{array}$ & $\begin{array}{c}-0,0053^{* * *} \\
(0,0009)\end{array}$ & $\begin{array}{c}-0,0223^{* * *} \\
(0,0018)\end{array}$ & $\begin{array}{c}-0,0291^{* * *} \\
(0,0036)\end{array}$ \\
\hline Taxa de urbanização & $\begin{array}{c}0,00002 \\
(0,00002)\end{array}$ & $\begin{array}{l}-0,0004^{* * *} \\
(0,00006)\end{array}$ & $\begin{array}{l}-7,03 e-06 \\
(0,00004)\end{array}$ & $\begin{array}{c}0,00007 \\
(0,00008)\end{array}$ & $\begin{array}{l}-0,0003^{*} \\
(0,0001)\end{array}$ \\
\hline Transferências sobre despesa & $\begin{array}{l}0,0182^{* * *} \\
(0,0035)\end{array}$ & $\begin{array}{c}0,0954 * * * \\
(0,0128)\end{array}$ & $\begin{array}{l}0,0573^{* * *} \\
(0,0085)\end{array}$ & $\begin{array}{c}0,0541^{* * *} \\
(0,0153)\end{array}$ & $\begin{array}{l}0,2075^{* * *} \\
(0,0362)\end{array}$ \\
\hline Constante & $\begin{array}{l}0,0179 * * * \\
(0,0053)\end{array}$ & $\begin{array}{l}0,0629 * * * \\
(0,02787)\end{array}$ & $\begin{array}{c}0,0716^{* * *} \\
(0,0171)\end{array}$ & $\begin{array}{l}0,3310^{* * *} \\
(0,0304)\end{array}$ & $\begin{array}{l}0,4815^{* * *} \\
(0,0742)\end{array}$ \\
\hline Amostra & 668 & 704 & 710 & 651 & 725 \\
\hline Estatística F & 28,35 & 103,36 & 83,32 & 66,09 & 100,14 \\
\hline Significância modelo & 0,00 & 0,00 & 0,00 & 0,00 & 0,00 \\
\hline $\mathrm{R}^{2}$ & 0,32 & 0,52 & 0,51 & 0,48 & 0,55 \\
\hline $\mathrm{R}^{2}$ ajustado & 0,31 & 0,51 & 0,50 & 0,47 & 0,55 \\
\hline
\end{tabular}

Fonte: Elaborada pelos autores com base em: dados de corrupção foram obtidos a partir do banco de dados do PFSP da CGU; despesas municipais obtidas a partir dos dados da STN base "Finbra" disponíveis em: <www.tesouro.fazenda.gov.br/pt/prefeituras-governos-esta- 
duais/sobre>. Acesso em: 27 mar. 2013; Índice de Gini: IBGE, Censo Demográfico 2000 e Pesquisa de Orçamentos Familiares - POF 2002/2003: <www.cidades.ibge.gov.br>. Acesso em: 4 abr. 2013; PIB municipal: <www.ipeadata.gov.br>. Acesso em: 27 mar. 2013 ; População: <www.ipeadata.gov.br>. Acesso em: 27 mar. 2013; Taxa de urbanização: IBGE, Censo demográfico 2010: <www.ibge.gov. br>. Acesso em: 4 abr. 2013.

Notas: Entre parênteses está o erro-padrão robusto, a heterocedasticidade e autocorrelação. * significativo a 10\%; ** significativo a 5\%; *** significativo a 1\%; (a) Não inclui as informações de constatações e transferências do "Programa Bolsa Família".

Tabela B

Resultados da regressão múltipla - modelo (2) - transferências da União aos municípios

\begin{tabular}{|c|c|c|c|c|c|}
\hline \multirow[b]{2}{*}{ Variáveis dependentes } & \multicolumn{5}{|c|}{ Transferências em percentual do PIB municipal } \\
\hline & $\begin{array}{l}\text { Assistência } \\
\text { Social (a) }\end{array}$ & Educação & Saúde & $\begin{array}{l}\text { Outras Transfe- } \\
\text { rências }\end{array}$ & $\begin{array}{l}\text { Transferências } \\
\text { Totais }\end{array}$ \\
\hline Corrupção & $\begin{array}{l}-0,0002^{* *} \\
(0,0001)\end{array}$ & $\begin{array}{c}0,0004^{* * *} \\
(0,0001)\end{array}$ & $\begin{array}{c}0,0002^{* * *} \\
(0,0001)\end{array}$ & $\begin{array}{c}0,0001 \\
(0,0001)\end{array}$ & $\begin{array}{c}0,0023^{* * *} \\
(0,0004)\end{array}$ \\
\hline Índice de Gini & $\begin{array}{l}-0,0025 \\
(0,0036)\end{array}$ & $\begin{array}{c}-0,1963^{* * *} \\
(0,0312)\end{array}$ & $\begin{array}{l}-0,0175 \\
(0,0149)\end{array}$ & $\begin{array}{c}-0,2401^{* * *} \\
(0,0678)\end{array}$ & $\begin{array}{l}-0,4113 * * * \\
(0,0903)\end{array}$ \\
\hline PIB municipal per capita & $\begin{array}{c}-3,60 \mathrm{e}-07^{* * *} \\
(7,49 \mathrm{e}-08)\end{array}$ & $\begin{array}{c}-3,25 \mathrm{e}-06 * * * \\
(5,89 \mathrm{e}-07)\end{array}$ & $\begin{array}{c}-1,81 \mathrm{e}-06^{* * *} \\
(3,24 \mathrm{e}-07)\end{array}$ & $\begin{array}{l}-0,0001^{* * *} \\
(1,10 \mathrm{e}-06)\end{array}$ & $\begin{array}{l}-0,0001^{* * *} \\
(2,23 e-06)\end{array}$ \\
\hline População & $\begin{array}{c}-0,0005^{* * *} \\
(0,0001)\end{array}$ & $\begin{array}{l}0,0061^{* * *} \\
(0,0010)\end{array}$ & $\begin{array}{l}0,0012^{* * *} \\
(0,0004)\end{array}$ & $\begin{array}{c}-0,0329 * * * \\
(0,0024)\end{array}$ & $\begin{array}{c}-0,0291^{* * *} \\
(0,0029)\end{array}$ \\
\hline Taxa de urbanização & $\begin{array}{l}-0,0001^{* * *} \\
(6,42 \mathrm{e}-06)\end{array}$ & $\begin{array}{c}-0,0004 * * * \\
(0,0001)\end{array}$ & $\begin{array}{c}-0,0001^{* * *} \\
(0,0002)\end{array}$ & $\begin{array}{l}-0,0001 \\
(0,0001)\end{array}$ & $\begin{array}{c}-0,0006^{* * *} \\
(0,0001)\end{array}$ \\
\hline Constante & $\begin{array}{l}0,0124^{* * *} \\
(0,0020)\end{array}$ & $\begin{array}{c}0,0857^{* * *} \\
(0,0119)\end{array}$ & $\begin{array}{c}0,0264^{* * *} \\
(0,0062)\end{array}$ & $\begin{array}{c}0,5550^{* * *} \\
(0,0338)\end{array}$ & $\begin{array}{c}0,6451^{* * *} \\
(0,0448)\end{array}$ \\
\hline Amostra & 737 & 774 & 781 & 715 & 797 \\
\hline Estatística F & 20,15 & 58,02 & 58,27 & 67,61 & 88,20 \\
\hline Significância modelo & 0,00 & 0,00 & 0,00 & 0,00 & 0,00 \\
\hline $\mathrm{R}^{2}$ & 0,23 & 0,42 & 0,37 & 0,52 & 0,52 \\
\hline $\mathrm{R}^{2}$ ajustado & 0,23 & 0,41 & 0,36 & 0,50 & 0,51 \\
\hline
\end{tabular}

Fonte: Elaborada pelos autores com base em: dados de corrupção obtidos a partir do banco de dados do PFSP da CGU; Transferências da União para municípios foram obtidas no Portal da Transparência do Governo Federal: <www.portaldatransparencia.gov.br >. Acesso em: 3 abr. 2013; Índice de Gini: IBGE, Censo Demográfico 2000 e Pesquisa de Orçamentos Familiares - POF 2002/2003: <www.cidades. ibge.gov.br>. Acesso em: 4 abr. 2013; PIB municipal: <www.ipeadata.gov.br>. Acesso em: 27 mar. 2013; População: <www.ipeadata. gov.br>. Acesso em: 27 mar. 2013; Taxa de urbanização: IBGE, Censo demográfico 2010: <www.ibge.gov.br>. Acesso em: 4 abr. 2013. Notas: Entre parênteses está o erro-padrão robusto, a heterocedasticidade e autocorrelação. * significativo a 10\%; ** significativo a 5\%; *** significativo a 1\%; (a) Não inclui as informações de constatações e transferências do "Programa Bolsa Família". 
Tabela C

Resultados da regressão múltipla - modelo (1) - despesas municipais

\begin{tabular}{|c|c|c|c|c|}
\hline \multirow[b]{2}{*}{ Variáveis dependentes } & \multicolumn{4}{|c|}{ Despesas em percentual da Despesa Total municipal } \\
\hline & $\begin{array}{l}\text { Assistência } \\
\text { Social (a) }\end{array}$ & Educação & Saúde & Outras Despesas \\
\hline Corrupção (a) & $\begin{array}{c}-0,0013^{* * *} \\
(0,0003)\end{array}$ & $\begin{array}{l}0,0004^{* * *} \\
(0,0001)\end{array}$ & $\begin{array}{l}-0,0001 \\
(0,0001)\end{array}$ & $\begin{array}{l}0,0003^{*} \\
(0,0002)\end{array}$ \\
\hline Índice de Gini & $\begin{array}{c}0,076^{* * *} \\
(0,024)\end{array}$ & $\begin{array}{c}-0,1717^{* *} \\
(0,0842)\end{array}$ & $\begin{array}{l}0,1005^{*} \\
(0,0568)\end{array}$ & $\begin{array}{l}-0,0375 \\
(0,0980)\end{array}$ \\
\hline PIB municipal per capita & $\begin{array}{c}2,00 \mathrm{e}-07 \\
(1,92 \mathrm{e}-07)\end{array}$ & $\begin{array}{c}-3,28 \mathrm{e}-06^{* * *} \\
(1,07 \mathrm{e}-06)\end{array}$ & $\begin{array}{c}-2,36 e-07 \\
(5,75 e-07)\end{array}$ & $\begin{array}{c}4,26 \mathrm{e}-06^{* * *} \\
(1,25 \mathrm{e}-06)\end{array}$ \\
\hline População & $\begin{array}{c}-0,0056^{* * *} \\
(0,0008)\end{array}$ & $\begin{array}{c}-0,0359 * * * \\
(0,0030)\end{array}$ & $\begin{array}{c}-0,0061^{* * *} \\
(0,0022)\end{array}$ & $\begin{array}{c}-0,0338^{* * *} \\
(0,0030)\end{array}$ \\
\hline Taxa de urbanização & $\begin{array}{l}0,0001^{* * *} \\
(0,00004)\end{array}$ & $\begin{array}{l}-0,001^{* * *} \\
(0,0001)\end{array}$ & $\begin{array}{l}0,0004^{* * *} \\
(0,00008)\end{array}$ & $\begin{array}{l}0,0005^{* * *} \\
(0,0001)\end{array}$ \\
\hline Transferências sobre despesa & $\begin{array}{c}0,0284^{* * *} \\
(0,0065)\end{array}$ & $\begin{array}{l}0,0849 * * * \\
(0,0209)\end{array}$ & $\begin{array}{c}0,0557^{* * *} \\
(0,0143)\end{array}$ & $\begin{array}{c}-0,1632^{* * *} \\
(0,0260)\end{array}$ \\
\hline Constante & $\begin{array}{c}0,0372^{* * *} \\
(0,0112)\end{array}$ & $\begin{array}{c}0,0596 \\
(0,0460)\end{array}$ & $\begin{array}{l}0,0667^{* *} \\
(0,0282)\end{array}$ & $\begin{array}{l}0,8179 * * * \\
(0,0498)\end{array}$ \\
\hline Amostra & 699 & 737 & 741 & 680 \\
\hline Estatística F & 13,33 & 79,11 & 10,54 & 54,52 \\
\hline Significância modelo & 0,00 & 0,00 & 0,00 & 0,00 \\
\hline $\mathrm{R}^{2}$ & 0,13 & 0,41 & 0,08 & 0,36 \\
\hline $\mathrm{R}^{2}$ ajustado & 0,12 & 0,41 & 0,07 & 0,35 \\
\hline
\end{tabular}

Fonte: Elaborada pelos autores com base em: dados de corrupção foram obtidos a partir do banco de dados do PFSP da CGU; despesas municipais obtidas a partir dos dados da STN base "Finbra" disponíveis em: <www.tesouro.fazenda.gov.br/pt/prefeituras-governos-estaduais/sobre>. Acesso em: 27 mar. 2013; Índice de Gini: IBGE, Censo Demográfico 2000 e Pesquisa de Orçamentos Familiares - POF 2002/2003: <www.cidades.ibge.gov.br>. Acesso em: 4 abr. 2013; PIB municipal: <www.ipeadata.gov.br>. Acesso em: 27 mar. 2013 ; População: <www.ipeadata.gov.br>. Acesso em: 27 mar. 2013; Taxa de urbanização: IBGE, Censo demográfico 2010: <www.ibge.gov. br>. Acesso em: 4 abr. 2013.

Notas: Entre parênteses está o erro-padrão robusto, a heterocedasticidade e autocorrelação. * significativo a 10\%; ** significativo a 5\%; *** significativo a 1\%; (a) Não inclui as informações de constatações e transferências do "Programa Bolsa Família". 


\begin{tabular}{|c|c|c|c|c|}
\hline \multirow[b]{2}{*}{ Variáveis dependentes } & \multicolumn{4}{|c|}{ Transferências em percentual da Transferência Total municipal } \\
\hline & $\begin{array}{c}\text { Assistência } \\
\text { Social (a) }\end{array}$ & Educação & Saúde & Outras Transferências \\
\hline \multirow{2}{*}{ Corrupção (a) } & $-0,0010^{* * *}$ & $0,0012^{* * *}$ & 0,0001 & $-0,0001$ \\
\hline & $(0,0002)$ & $(0,0002)$ & $(0,0001)$ & $(0,0002)$ \\
\hline \multirow{2}{*}{ Índice de Gini } & $0,0525^{* * *}$ & $-0,4686^{* * *}$ & $0,1942^{* *}$ & $0,2317^{*}$ \\
\hline & $(0,0142)$ & $(0,1091)$ & $(0,0821)$ & $(0,1296)$ \\
\hline \multirow{2}{*}{ PIB municipal per capita } & $-7,84 \mathrm{e}-07 * * *$ & $-7,28 \mathrm{e}-06^{* * *}$ & $-8,88 \mathrm{e}-07$ & $0,00001^{* * *}$ \\
\hline & $(1,31 \mathrm{e}-07)$ & $(1,14 \mathrm{e}-06)$ & $(6,15 e-07)$ & $(1,34 \mathrm{e}-06)$ \\
\hline \multirow{2}{*}{ População } & $-0,0005$ & $-0,0526^{* * *}$ & $0,0420^{* * *}$ & $-0,0953 * * *$ \\
\hline & $(0,0004)$ & $(0,0034)$ & $(0,0036)$ & $(0,0040)$ \\
\hline \multirow{2}{*}{ Taxa de urbanização } & $-0,0001^{* * *}$ & $-0,0014^{* * *}$ & 0,0001 & $0,0014^{* * *}$ \\
\hline & $(0,00002)$ & $(0,0001)$ & $(0,0001)$ & $(0,0001)$ \\
\hline \multirow{2}{*}{ Constante } & 0,0014 & $-0,0297$ & $-0,3418^{* * *}$ & $1,3401^{* * *}$ \\
\hline & $(0,0050)$ & $(0,0379)$ & $(0,0315)$ & $(0,0456)$ \\
\hline Amostra & 775 & 813 & 820 & 750 \\
\hline Estatística F & 18,19 & 128,34 & 62,27 & 175,65 \\
\hline Significância modelo & 0,00 & 0,00 & 0,00 & 0,00 \\
\hline $\mathrm{R}^{2}$ & 0,12 & 0,46 & 0,40 & 0,56 \\
\hline $\mathrm{R}^{2}$ ajustado & 0,11 & 0,45 & 0,39 & 0,56 \\
\hline
\end{tabular}

Fonte: Elaborada pelos autores com base em: dados de corrupção foram obtidos a partir do banco de dados do PFSP da CGU; despesas municipais obtidas a partir dos dados da STN base "Finbra" disponíveis em: <www.tesouro.fazenda.gov.br/pt/prefeituras-governos-estaduais/sobre>. Acesso em: 27 mar. 2013; Índice de Gini: IBGE, Censo Demográfico 2000 e Pesquisa de Orçamentos Familiares - POF 2002/2003: <www.cidades.ibge.gov.br>. Acesso em: 4 abr. 2013; PIB municipal: <www.ipeadata.gov.br>. Acesso em: 27 mar. 2013 ; População: <www.ipeadata.gov.br>. Acesso em: 27 mar. 2013; Taxa de urbanização: IBGE, Censo demográfico 2010: <www.ibge.gov. br>. Acesso em: 4 abr. 2013.

Notas: Entre parênteses está o erro-padrão robusto, a heterocedasticidade e autocorrelação. * significativo a 10\%; ** significativo a 5\%; *** significativo a 1\%; (a) Não inclui as informações de constatações e transferências do "Programa Bolsa Família". 